\title{
Colloid Titration for Determining the Surface Charge of Bacterial Spores
}

\author{
By K. WATANABE AND S. TAKESUE \\ Institute of Microbiology, Faculty of Pharmaceutical Sciences, \\ Fukuoka University, Fukuoka, Japan
}

(Received 3 March 1976; revised Io May 1976)

INTRODUCTION

Colloid titration was originally devised by Terayama (1948) for studying the colloidal polyelectrolytes. However, the potential of this technique was not fully exploited until Senju (1969) introduced titration reagents of higher molecular weight and adequate purity, and confirmed its usefulness. It has now become a valuable analytical technique for many colloidal polyelectrolytes such as agar, lignin, pectin and some proteins. Recently, colloid titration was used to determine the surface charge of some yeasts (Imahara, Iwai \& Nakahama, 197I) and of Micrococcus lysodeikticus (Katayama et al., I975).

To learn more about the mechanism of germination of bacterial spores, we have investigated the surface structure of two types of Bacillus megaterium spores that differ in their response to germinants and inhibitors. We found that the spores of QM-BI 55I strain (designated GN spores), which respond germinatively to glucose and $\mathrm{KNO}_{3}$, have more ionizable groups than those of ATCC192I3 strain (AL spores), which respond to L-alanine and inosine; and that the buffer action of GN spores against a change in hydrogen-ion concentration is substantially stronger than that of AL spores (Watanabe \& Takesue, 1970). Since the surface charge of spores may affect the initiation of germination, we examined whether colloid titration could be used to determine the surface charge of bacterial spores, and then determined the surface charge in terms of the colloid titration value of the two types of Bacillus megaterium spores.

\section{METHODS}

Bacillus megaterium ATCCI92I3 (designated AL strain in this paper) and QM-BI55I (GN strain) were provided by Professor L. J. Rode, University of Texas. Spores were produced on an agar medium as described by Rode \& Foster (1960). After three days incubation at $30^{\circ} \mathrm{C}$, the spores were harvested in deionized water and washed eight times with water by centrifugation in the cold. Concentrated suspensions of cleaned spores, confirmed by phasecontrast microscopy, were lyophilized.

Colloid titration is based on the phenomenon that positively and negatively-charged colloidal particles combine stoicheiometrically with each other and the end point of a titration can be detected with a suitable indicator. Protamine sulphate (PS) was used as a positive colloidal reagent and potassium polyvinyl sulphate (PVS-K; polymerization $n=\mathrm{I} 500$, esterification $98.4 \%$, certificated by Wako Jun-Yaku Co. Japan) as a negative reagent. For titrating negatively-charged colloidal particles such as bacterial spores, an excess (electrically) of $2.5 \mathrm{~mm}$-PS ( $5 \mathrm{ml}$ ) was added to an appropriate concentration of spores (e.g. $5 \mathrm{ml}$ at $2 \mathrm{mg} \mathrm{ml}^{-1}$ ) in deionized water or sometimes in $143 \mathrm{~mm}$-veronal acetate buffer. The unneutralized PS was back-titrated with $\mathrm{I} \cdot 0 \mathrm{~mm}-\mathrm{PVS}-\mathrm{K}$ using toluidine blue as indicator. 


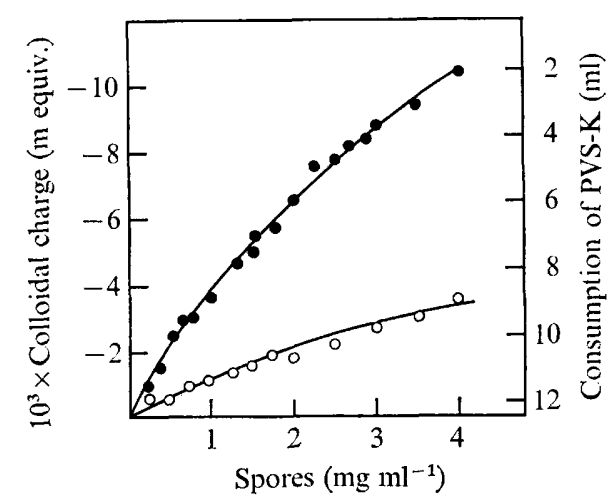

Fig. I

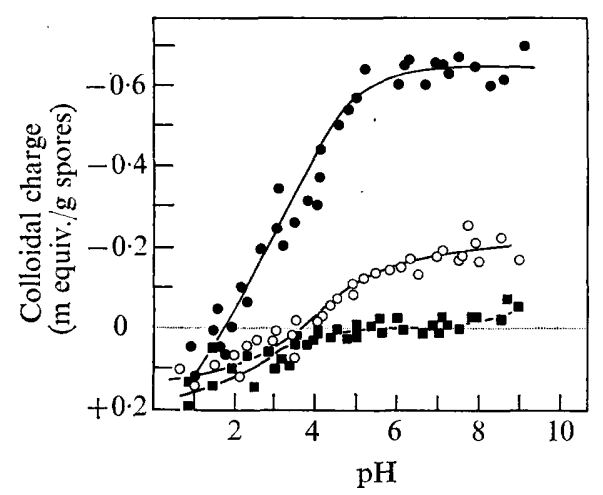

Fig. 2

Fig. I. Relationship between spore concentration and the colloid titration value. Graded amounts of spores $(1 \cdot 25$ to $20 \cdot 0 \mathrm{mg})$ were suspended in water $(5 \mathrm{ml})$ and the colloid titration was conducted at pH 6.0 with $2.5 \mathrm{~mm}-\mathrm{PS}(5 \mathrm{ml})$ and $\mathrm{r} \cdot 0 \mathrm{mM}-\mathrm{PVS}-\mathrm{K}$. Spores: $9, \mathrm{GN} ; \mathrm{O}, \mathrm{AL}$.

Fig. 2. pH-colloidal charge curve of spores. An aqueous suspension of spores (IO $\mathrm{mg}$ in $5 \mathrm{ml}$ ) was adjusted to various $\mathrm{pH}$ values with $\mathrm{HCl}$ and $\mathrm{NaOH}$, and the colloid titration was conducted with 2.5 mM-PS ( $5 \mathrm{ml}$ ) and I.O mM-PVS-K. Spores: 0 , GN; $O$, AL; $\boldsymbol{\square}$, control (no spores).

The end point was indicated both by metachromasy (the colour change of toluidine blue from blue to red-violet) and by aggregation of the spores. The value of the colloidal charge was expressed as milliequivalents per gramme of spores (m equiv./g spores), using standardized PVS-K as a criterion for titration.

\section{RESULTS AND DISCUSSION}

To test whether colloid titration is applicable for the quantitative determination of the surface charge of bacterial spores, various amounts of spores suspended in $5 \mathrm{ml}$ deionized water were titrated by the technique described in Methods. The titration value depended on the spore concentration (Fig. I). Both the GN and AL spores were found to be charged negatively and the magnitude of their negative charge increased almost linearly with spore concentration to $4 \mathrm{mg} \mathrm{ml}^{-1}$ under the conditions used. This indicated that colloid titration by this method could be used for bacterial spores. In the following experiments, a spore suspension at a final concentration of $2 \mathrm{mg} \mathrm{ml}^{-1}$ was used. Of the positive collcidal commercially available reagents tested, protamine sulphate was the most useful; others such as glycol chitosan and methyl glycol chitosan were unsuitable because they did not give a sharp colour change at the end point.

The titration value of GN spores was about three times that of AL spores (Fig. I). This indicated that about three times as many negatively charged groups were located on the surface of GN spores as on AL spores, although the contribution of cationic groups, such as the amino group, to the surface charge was not known. According to Kondo \& Nishihara (1970), the outer layer of the coat of GN spores is composed mainly of galactosamine-containing phosphomucopeptide, and its phosphorous content is about four times that of AL spores. The high phosphorous content of the outer layer in GN spores may be related to the fact that the surface is more negatively charged and the buffer action against a change in $\mathrm{pH}$ is stronger than in AL spores.

The degree of dissociation of weakly dissociable groups changes with the concentration of 
hydrogen ions in the environment, and, since colloid titration is concerned with weakly dissociated groups on the surface of colloidal particles, the titration value must be influenced by the $\mathrm{pH}$ of the surroundings. Therefore, colloid titration of the spores suspended in water and adjusted to different $\mathrm{pH}$ values with $\mathrm{HCl}$ and $\mathrm{NaOH}$ was conducted to determine the optimum conditions. The isoelectric points of the spores were also determined. The highest titration values were obtained at $\mathrm{pH}$ values above 6 with both types of spores (Fig. 2). No appreciable change in the titration value was observed between $\mathrm{pH} 6$ and 9 (the plateau region). When $\mathrm{I} 43 \mathrm{~mm}$-veronal acetate buffer was used instead of $\mathrm{HCl}$ and $\mathrm{NaOH}$ to adjust the $\mathrm{pH}$, the $\mathrm{pH}$-colloidal charge curve was almost the same. For GN spores, the colloidal charge at $\mathrm{pH}$ values in the plateau region was about $-0.6 \mathrm{~m}$ equiv./g spores. At $\mathrm{pH}$ values below 5, the negative charge decreased rapidly. In the $\mathrm{pH}$ range about $\mathrm{I}$ or 2 , it was slightly positive, showing that the isoelectric point of GN spores lies in that region. Accurate values for the isoelectric point could not be obtained, because the charge of the control (protamine sulphate solution without spores) did not remain constant in the tested $\mathrm{pH}$ range (Fig. 2), and, especially at the lower $\mathrm{pH}$ values, it tended to reverse and varied significantly between experiments. The general shape of the curve for AL spores was similar to that for GN spores, but both the negative charge at optimum $\mathrm{pH}$ (about $-0.2 \mathrm{~m}$ equiv/g spores) and the ioselectric point ( $\mathrm{pH}_{3}$ to 4 ) were different.

Since GN spores were more heat-resistant than AL spores (Rode, I968) and the outer layer of the coat of GN spores was thicker than that of AL spores (Kawasaki, Nishihara \& Kondo, 1970), it seemed that there might be a difference in resistance to mechanical shock between the two types of spores. However, subjecting the spores of either type to several cycles of freezing and thawing did not cause any change in their colloidal charge. The colloidal charges of spores suspended in water were not altered by storage for 6 months in a refrigerator, indicating that their surface structures were stable over long periods.

The authors wish to thank Professor H. Imahara, Kyoto College of Pharmacy, for his helpful advice on this work. They acknowledge the assistance of the following undergraduate students of Fukuoka University with some of the experiments: M. Fukudome, K. Kanamasa, H. Obata, K. Sekiya, Y. Wada, and M. Yokoyama.

\section{REFERENCES}

Imahara, H., IwaI, M. \& Nakahama, T. (197I). Studies on the pellicle-producing soy yeast. IX. Relationship between the physico-chemical properties and the pellicle formation of yeast. (In Japanese.) Hakko Kougaku Zasshi 48, 8-I5.

Katayama, T., Takai, K., Okabe, A., Hayashi, H. \& Kanamasa, Y. (1975). Application of a new colloid titrant to biological materials. (In Japanese.) Nihon Saikingaku Zasshi 30, 121.

KaWASAKI, C., Nishihara, T. \& Kondo, M. (1970). Studies on the bacterial spore coat. I. Morphological structure of spore coat of Bacillus megaterium. (In Japanese.) Nihon Saikingaku Zasshi 25, 209-2 I4.

Kondo, M. \& NishinaRA, T. (1970). Studies on the bacterial spore coat. 2. Chemical structures of fractions isolated from the dormant spore coat of Bacillus megaterium. (In Japanese.) Nihon Saikingaku Zasshi 25 , 2I 5-22I.

Rode, L. J. (1968). Correlation between spore structure and spore properties in Bacillus megaterium. Journal of Bacteriology 95, 1979-1986.

Rode, L. J. \& FoSTER, J. W. (1960). Mechanical germination of bacterial spores. Proceedings of the National Academy of Sciences of the United States of America 46, I I 8-1 28.

Senju, R. (1969). In Colloid Titration, pp. 3-5I. (In Japanese.) Edited by R. Senju. Tokyo: Nankoudo Co.

Terayama, H. (1948). General method of colloid titration. (In Japanese.). Kagaku No Kenkyu r, 75-I I6.

Watanabe, K. \& TAKesue, S. (1970). Surface charges of two types of Bacillus megaterium spores differing in their response to $n$-butane. Journal of General Microbiology 63, 375-377. 